\title{
Horner's Syndrome after Thyroidectomy: Two Cases Report
}

\section{Lei Huang, Xiaoqiao Tang, Lei Su*}

Department of General Surgery, The Affiliated Drum Tower Hospital, Medical School of Nanjing University, Nanjing, China

Email: huanglei_ramond@163.com, 102591085@qq.com, *sulei_njglyy@163.com

How to cite this paper: Huang, L., Tang, X.Q. and Su, L. (2018) Horner's Syndrome after Thyroidectomy: Two Cases Report. Open Journal of Preventive Medicine, 8 , 325-329.

https://doi.org/10.4236/ojpm.2018.812028

Received: November 15, 2018

Accepted: December 18, 2018

Published: December 21, 2018

Copyright $\odot 2018$ by authors and Scientific Research Publishing Inc. This work is licensed under the Creative Commons Attribution International License (CC BY 4.0).

http://creativecommons.org/licenses/by/4.0/

\begin{abstract}
Background: Horner's syndrome is defined as a combination of a series of symptoms following the injury of oculosympathetic pathway. This dysfunction is usually acquired during cervical surgery but rarely triggered by thyroid-surgery. Case Presentation: Here we present two cases secondary to thyroidectomy. Two young female patients, both diagnosed as tumor in left lobe of thyroid, had Horner's syndrome after surgery. Fortunately, Horner's syndrome was relieved after steroid treatment. Conclusions: Indirect mechanism involved in the lesion and the direct factor with mistaken section of nerve fibers may be responsible for Horner's syndrome. Besides, Horner's syndrome after thyroid surgery may be revisable after oral steroid treatment.
\end{abstract}

\section{Keywords}

Honer's Syndrome, Thyroidectomy

\section{Introduction}

Horner's syndrome (HS), characterized by a combination of myosis, ipsilateral blepharoptosis, enophthalmos, facial anhydrosis, and vascular dilation of the lateral part of the face, was first described by Johann Friedrich Horner in 1869 [1] [2] [3]. Lately, this series of symptoms was caused by the interruption of oculosympathetic pathway (OSP) [4]. HS has been reported to arise following cervical surgery [2]. In generally, the surgical procedures triggering this syndrome are carotid endarterectomy and cervical spine surgery via an anterior approach. However, thyroid-surgery associated HS is rare [5] [6]. Here, we reported two cases of Horner's syndrome after thyroidectomy. 


\section{Case Report}

Case one: a 23-year-old female was found to have a mass of $2.6 \times 1.6 \times 1.6 \mathrm{~cm}$ in left lobe of thyroid. Ultrasonography showed that the mass was hypoechoic and irregular. Fine-needle aspiration (FNA) in the left lobe region mass was disclosed as papillary thyroid cancer. The patient underwent total thyroidectomy with bilateral radical neck dissection on October 28, 2015. The postoperative pathology showed thyroid papillary carcinoma (TNM). On post operative day 2 , the patient presented with left palpebral ptosis and pupillary miosis but no facial anhidrosis (Figure 1(a)). Steroid tablets were given orally. After one week, the patient's symptoms of Horner's syndrome were relieved. However, the left pupil was still smaller than before. During 2 years of follow-up, the left pupil was approximately normal (Figure $1(\mathrm{~b})$ ).

Case two: a 32-year-old female presented with a day's history of left neck mass. Physical examination revealed a firm fixed $1 \mathrm{~cm}$ mass in the left lobe in thyroid region. Ultrasonography showed left lobe substantial mass in thyroid (TI-RADS level 5) with multiple abnormal left neck lymph nodes. Video-assisted thyroidectomy with central compartment and left lateral lymph nodes dissection were performed on August 31, 2017. The postoperative pathologyy showed thyroid papillary carcinoma of $0.7 \times 0.6 \times 0.4 \mathrm{~cm}$ and lymph nodes metastasis. On post operative day 2, the patient had developed Horner's syndrome with left palpebral ptosis and pupillary miosis without facial anhidrosis (Figure 2(a)). Steroid tablets were given orally for one week, after 8 days of treatment, the patient's symptoms of Horner's syndrome were relieved obviously (Figure 2(b)).

\section{Discussion}

Horner's syndrome is rarely reported in patients receiving thyroidectomy. As of 2008 , HS following conventional thyroidectomy was appeared in $0.2 \%$ to $0.27 \%$

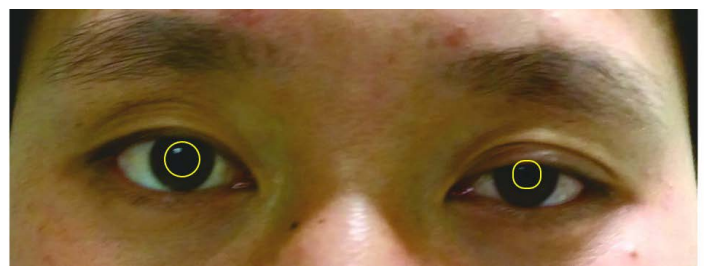

(a)

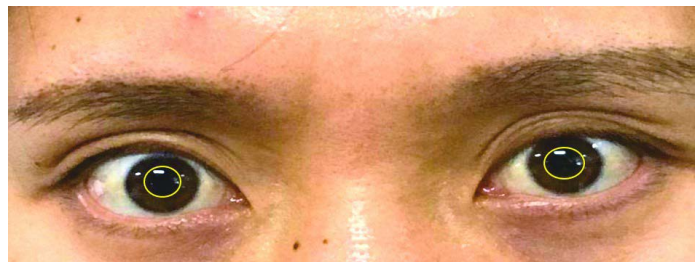

(b)

Figure 1. Case 1: (a) Horner's syndrome (2 days after surgery). (b) Horner's syndrome (2 years after surgery). A pictorial circle along the pupil border was marked to see the comparison of the pupil size between the eyes. 


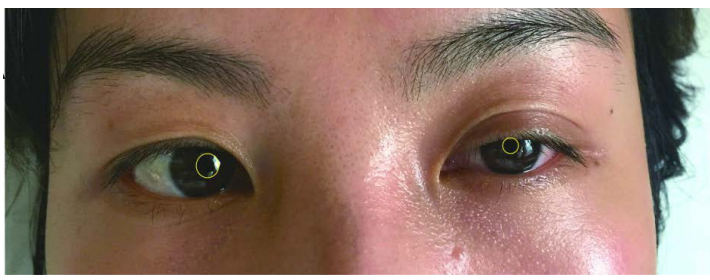

(a)

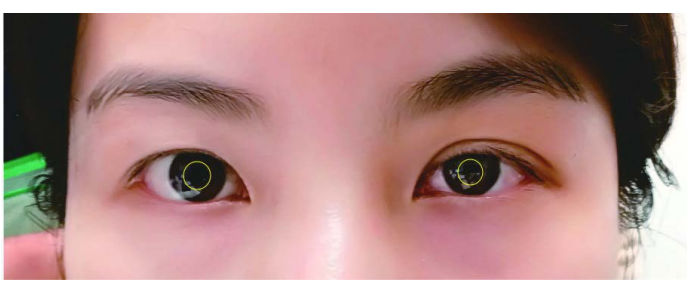

(b)

Figure 2. Case 2: (a) Horner's syndrome (2 days after surgery). (b) Horner's syndrome (8 days after surgery). A pictorial circle along the pupil border was marked to see the comparison of the pupil size between the eyes.

cases [3]. In Korea, two retrospective studies indicated the incidence rate of HS as $0.2 \%$ and $0.03 \%$ separately [7] [8]. In China, this number has not been calculated systmaticlly. Horner's syndrome, characterized by ipsilateral palpebral ptosis, pupillary miosis and facial anhidrosis, is caused by damage to sympathetic nerve pathway [2] [9] [10]. Generally, the sympathetic nerves mainly consist of three grades neurons. The first grade neurons are located in the hypothalamus, the second grade neurons form the neck's sympathetic chain, and the third grade neurons emit postganglionic axons that reach to the eye part. The most common mechanism of injury of the cervical sympathetic nerve is direct involvement of tumor of inflammation lesions, and the most common sites are prevertebral fascia, paratracheal area, posteromedial area of the carotid sheath, and lung apex [11]. Many studies have reported that Horner syndrome appeared after cervical surgery, but thyroid-surgery associated Horner syndrome is rare [12] [13]. In this report, we presented two typical Horner's syndrome after thyroid surgery. And both of them recovered partly or completely by oral steroid treatment after a period of time.

To our knowledge, Horner's syndrome may be caused not only by mechanical stress directly, but also by an anastomosis lesion indirectly [14] [15]. In our cases, both of them underwent thyroidectomy and cervical lymph node dissection, and then presented classical Horner's syndrome after surgery. Thus, it was speculated that the indirect mechanism involved in the lesion and the direct factor with mistaken section of nerve fibers may be responsible for this syndrome.

Therefore, for the purpose of avoiding cervical sympathetic nerve damage, it is necessary to be familiar with cervical anatomy and be careful during the dissection of lymph nodes. It is also requisite to be acquainted with the related anastomosis just in case. Moreover, both of our patients recovery better than before after oral steroid treatment, which reminds us Horner's syndrome after thyroid 
surgery may be revisable. This result also emphasized that Horner's syndrome could be prevented effectively.

\section{Conclusion}

Horner's syndrome is a rare complication of thyroid surgery; patients should be informed of this complication before surgery.

\section{Consent for Publication}

Patients mentioned in this article agree with the publication.

\section{Availability of Data and Material}

The datasets used and/or analysed during the current study are available from the corresponding author on reasonable request.

\section{Authors' Contributions}

LH was a major contributor in writing the manuscript. XQT provided images for this article. LS revised this manuscript and was responsible for this work.

\section{Conflicts of Interest}

The authors declare that they have no competing interests.

\section{References}

[1] Coskun, M., Aydogan, A., Gokce, C., Ilhan, O., Ozkan, O.V., Gokce, H. and Oksuz, H. (2013) Irreversible Horner's Syndrome Diagnosed by Aproclonidine Test Due to Benign Thyroid Nodule. Pakistan Journal of Medical Sciences, 29, 224-226.

[2] González-Aguado, R., Morales-Angulo, C., Obeso-Agüera, S., Longarela-Herrero, Y., García-Zornoza, R. and Acle Cervera, L. (2012) Horner's Syndrome after Neck Surgery. Acta Otorrinolaringológica Española, 63, 299-302.

https://doi.org/10.1016/j.otorri.2012.01.015

[3] Cozzaglio, L., Coladonato, M., Doci, R., Travaglini, P., Vizzotto, L., Osio, M. and Gennari, L. (2008) Horner's Syndrome as a Complication of Thyroidectomy: Report of a Case. Surgery Today, 38, 1114-1116. https://doi.org/10.1007/s00595-007-3741-z

[4] Giannaccare, G., Gizzi, C. and Fresina, M. (2016) Horner Syndrome Following Thyroid Surgery: The Clinical and Pharmacological Presentations. Journal of Ophthalmic \& Vision Research, 11, 442-444. https://doi.org/10.4103/2008-322X.194146

[5] Demiral, M., Binay, C., Simsek, E. and Ilhan, H. (2017) Horner Syndrome Secondary to Thyroid Surgery. Case Reports in Endocrinology, 2017, Article ID: 1689039. https://doi.org/10.1155/2017/1689039

[6] Cho, S.H., Kim, S.H., Lee, J.H., Joo, W.I., Chough, C.K., Park, H.K., Lee, K.J. and Rha, H.K. (2014) Brain Metastases of Papillary Thyroid Carcinoma with Horner's Syndrome. Brain Tumor Research and Treatment, 2, 132-137. https://doi.org/10.14791/btrt.2014.2.2.132

[7] Lee, Y.S., Nam, K.H., Chung, W.Y., Chang, H.S. and Park, C.S. (2010) Postoperative Complications of Thyroid Cancer in a Single Center Experience. Journal of Korean Medical Science, 25, 541-545. https://doi.org/10.3346/jkms.2010.25.4.541 
[8] Ban, E.J., Yoo, J.Y., Kim, W.W., Son, H.Y., Park, S., Lee, S.H., Lee, C.R., Kang, S.W., Jeong, J.J., Nam, K.H., Chung, W.Y. and Park, C.S. (2014) Surgical Complications after Robotic Thyroidectomy for Thyroid Carcinoma: A Single Center Experience with 3,000 Patients. Surgical Endoscopy, 28, 2555-2563.

https://doi.org/10.1007/s00464-014-3502-1

[9] Ying, X., Dandan, G. and Bin, C. (2013) Postoperative Horner's Syndrome after Video-Assisted Thyroidectomy: A Report of Two Cases. World Journal of Surgical Oncology, 11, 315. https://doi.org/10.1186/1477-7819-11-315

[10] Vilallonga, R., Fort, J.M., Mazarro, A., Gonzalez, O., Caubet, E., Romero, G. and Armengol, M. (2012) Postthyroidectomy Horner's Syndrome. Case Reports in Medicine, 2012, Article ID: 316984. https://doi.org/10.1155/2012/316984

[11] Civelek, E., Karasu, A., Cansever, T., Hepgul, K., Kiris, T., Sabanci, A. and Canbolat, A. (2008) Surgical Anatomy of the Cervical Sympathetic Trunk During Anterolateral Approach to Cervical Spine. European Spine Journal, 17, 991-995. https://doi.org/10.1007/s00586-008-0696-8

[12] Meng, K., Tian, W., Lv, Z. and Song, X. (2015) Horner's Syndrome Subsequent to Minimally Invasive Video-Assisted Thyroidectomy in Two Patients. Oncology Letters, 10, 459-462. https://doi.org/10.3892/ol.2015.3159

[13] De Silva, W.D., De Soysa, M.S. and Perera, B.L. (2010) Iatrogenic Horner's Syndrome: A Rare Complication of Thyroid Surgery. Ceylon Medical Journal, 55, 136. https://doi.org/10.4038/cmj.v55i4.2639

[14] Kahraman, A., Yildirim, I., Kiliç, M.A., Okur, E. and Demirpolat, G. (2009) Horner's Syndrome from Giant Schwannoma of the Cervical Sympathetic Chain: Case Report. B-ENT, 5, 111-114.

[15] Olson, J.A. (1999) Walsh and Hoyt's Clinical Neuro-Ophthalmology. British Journal of Ophthalmology, 83, Article ID: 1096D.

\section{List of Abbreviations}

Horner's syndrome (HS)

Oculosympathetic pathway (OSP)

Thyroid papillary carcinoma (TNM)

Fine-needle aspiration (FNA)

Thyroid imaging reporting and data system (TI-RADS) 